\title{
Consumo e Cidadania:
}

\section{em perspectiva a recepção do rap da periferia paulistana}

\author{
Maria Aparecida Baccega \\ Livre-Docente em Comunicação pela Escola de Comunicações e Artes da USP. Docente, \\ pesquisadora e orientadora do Programa de Pós-Graduação em Comunicação e Práticas de \\ Consumo da Escola Superior de Propaganda e Marketing SP. E-mail: mabga@usp.br
}

Fernanda Elouise Budag

Doutoranda em Ciências da Comunicação pela ECA-USP. Docente da Faculdade Paulus de Tecnologia e Comunicação (FAPCOM).

E-mail: fernanda.budag@gmail.com

Rosilene Moraes Alves Marcelino

Doutoranda em Comunicação e Semiótica pela PUC-SP. Docente da ESPM-SP.

E-mail: rosilene.marcelino@outlook.com

Maria Amélia Paiva Abrão

Mestre em Comunicação e Práticas de Consumo pela ESPM-SP.

E-mail: amelia.abrao@gmail.com

Resumo: Nossa pesquisa, em sua totalidade, procurou compreender como a cultura midiática e de consumo figuram nas narrativas (letras das músicas) de um grupo de rap da periferia de São Paulo e como são recebidas entre jovens da capital paulista, procurando entender os sentidos de consumo e de cidadania que aí se constituem. Para isso, a pesquisa buscou (a) articular, teoricamente, os vértices da Comunicação, da Educação, do Consumo e da Cidadania; (b) compreender - lugar de fala do grupo em questão; (c) analisar as produções desse grupo de rap da periferia de São Paulo e (d) realizar um estudo de recepção dessa vertente musical entre jovens paulistanos. Neste espaço, especificamente, traçamos os resultados do estudo de recepção empreendido.

Palavras-chave: comunicação e práticas de consumo; educação e cidadania; culturas urbanas; música; rap.
Abstract: Our research, in its entirety, sought to understand how media and consumption culture appear in the narratives (lyrics) of a rap group from the periphery of São Paulo and how they are received between young people from the state capital, trying to understand consumption and citizenship senses that they contain. For this, the research sought: (a) to articulate theoretically the vertices of Communication, Education, Consumption and Citizenship; (b) to understand the place of speech of the group discussed; (c) to analyze the productions of this rap group from the periphery of São Paulo; and (d) to conduct a reception study of this musical genre among the young people from São paulo. In this paper, more specifically, we outlined the results of the reception study undertaken.

Keywords: communication and consumption practices; education and citizenship; urban cultures; music; rap.
Recebido: 25/02/2015 
comunicação \& educação • Ano XX • número 2 • jul/dez 2015

1 Os resultados da primeira etapa da pesquisa estão publicados em: BUDAG, Fernanda Elouise; JUNQUEIRA, Antonio Helio; MARCELINO, Rosilene Moraes Alves. Comunicação, educação, práticas de consumo e cidadania: em perspectiva o rap da periferia paulistana. Comunicação \& Educação, v. 19 , p. 93-102, 2014.

2. LETRAS. "A vida é um desafio". Disponível em: $<$ http://letras.mus.br/racionais-mcs/66802>. Acesso em: 12 dez. 2013. LETRAS. "Capítulo 4, versículo 3". Disponivel em: <http:// letras.mus.br/racionais$\mathrm{mcs} / 66643>$. Acesso em: 12 dez. 2013. LETRAS.

"Fórmula mágica da paz". Disponível em: <http:// letras.mus.br/racionaismcs/63401>. Acesso em: 12 dez. 2013. LETRAS. "Mágico de Oz". Disponível em: <http://letras.mus. $\mathrm{br} /$ racionais-mcs/63399> Acesso em: 12 dez. 2013. LETRAS. "Periferia é periferia". Disponível em: <http:// letras.mus.br/racionaismcs/72468>. Acesso em: 12 dez. 2013. LETRAS. "Racionais otários". Disponível em: <http://letras.mus.br/ racionais-mcs/796245>. Acesso em: 12 dez. 2013 LETRAS. "Tô ouvindo alguém me chamar". Disponível em: <http://letras.mus. $\mathrm{br} /$ racionais-mcs/63438>

Acesso em: 12 dez. 2013. LETRAS. "Vida loka (parte 1)". Disponível em: <http:// letras.mus.br/racionais-mcs/64916>. Acesso em: 12 dez. 2013. LETRAS

"Vida loka (parte 2)". Disponivel em: <http:// letras.mus.br/racionaismcs/64917>. Acesso em: $12 \mathrm{dez}$. 2013. VAGALUME. Biografia Racionais MC's. Disponível em: <www. vagalume.com.br/racionais$\mathrm{mcs} /$ biografia>. Acesso em: set. 2013. VAGALUME.

"Crime vai e vem". Disponível em: <www.vagalume. com.br/racionais-mcs/cri me-vai-o-crime-vem.html>. Acesso em: 12 dez. 2013.

\section{INTRODUÇÃO}

O presente relato expõe os resultados da segunda etapa (estudo de recepção) de uma pesquisa que se propôs a investigar o rap como uma vertente do universo simbólico do hip $h o p^{1}$. Mais especificamente, o estudo analisou, a partir de revisão de literatura e da perspectiva da Análise de Discurso de linha francesa, as produções de um grupo de rap da periferia de São Paulo - o Racionais MC's - na intenção de compreender como a cultura midiática e a de consumo figuram em suas narrativas (letras das músicas ${ }^{2}$ ) e também como são recebidas entre jovens da capital paulista, para, assim, entender como se constroem os sentidos de consumo e de cidadania.

Nesse contexto, estruturamos o estudo em três etapas metodológicas: pesquisa bibliográfica, pesquisa documental e pesquisa de campo. A pesquisa bibliográfica foi caracterizada por uma revisão de literatura em torno de conceitos e autores que discutem as temáticas afins ao nosso objeto de estudo, agregando-lhe sustentação. E na segunda etapa, pesquisa documental, fizemos um levantamento de músicas do grupo Racionais MC's que foram analisadas segundo o aporte teórico da Análise de Discurso de linha francesa (ADF).

Já na terceira etapa, que é, de fato, nosso interesse expor aqui, adotamos como técnica de abordagem em campo o grupo focal. Tal técnica permite maior aprofundamento das questões de interesse em uma pesquisa. Conforme situa Costa, "grupos focais são um tipo de pesquisa qualitativa que tem como objetivo perceber os aspectos valorativos e normativos que são referência de um grupo em particular" ${ }^{3}$. E, em nosso caso, trata-se de técnica de pesquisa que operacionaliza o estudo de recepção proposto. Da mesma forma que as letras das músicas, os depoimentos coletados no grupo focal foram analisados a partir dos princípios da Análise de Discurso.

Ao elegermos a ADF como base analítica de nosso corpus, reconhecemos a linguagem como aspecto-chave para a compreensão de nossa realidade, visto constituir-se como espaço de articulação tanto de processos ideológicos como de fenômenos linguísticos ${ }^{4}$. Endossamos neste projeto a perspectiva de Orlandi ${ }^{5}$, para quem as "palavras simples do cotidiano já chegam até nós carregadas de sentidos que não sabemos como se constituíram e que no entanto significam em nós e para nós” ${ }^{6}$.

\section{DA COMUNICAÇÃO, DA EDUCAÇÃO, DO CONSUMO E DA CIDADANIA}

Amarrando pontos-chave de nosso estudo, a questão-problema de nossa pesquisa se situa na conexão entre os eixos Comunicação, Educação, Consumo e Cidadania. Dessa forma, antes de adentrarmos num quadro de análises e resultados, construímos mais nosso alicerce teórico com base em princípios norteadores afins a esses eixos centrais - a partir dos quais depois enxergaremos criticamente nosso corpus. 
Ampliando uma construção conceitual em torno da cidadania, Dagnino ${ }^{7}$ propõe uma noção renovada que supera a relação que se pressupunha com o Estado. Segundo a autora, cidadania deve ir além da

reivindicação de acesso, inclusão, membership, "pertencimento" (belonging) ao sistema político, na medida em que o que está de fato em jogo é o direito de participar efetivamente da própria definição desse sistema, o direito de definir aquilo no qual queremos ser incluídos, a invenção de uma nova sociedade" [grifos do autor $]^{8}$.

Assim, cidadania deve ser hoje enxergada como uma prática social de construção de cidadãos enquanto sujeitos ativos em sociedade. E essa construção se consegue passando pela Educação, que, por sua vez, neste espaço, dialoga com a Comunicação, numa tentativa de arquitetar um campo que avance, não só, mas também, na construção de Cidadania. Para a formação de cidadãos.

Esse campo - Comunicação e Educação - está interessado justamente em problematizar o que circula no âmbito da comunicação, do universo midiático e evidenciar a produção de significados tanto por parte do produtor quanto por parte do receptor. Ou, conforme coloca Baccega: "Mais que isso: é preciso falar, agora, dessa construção de sentidos sociais que se dá no encontro produtos midiáticos/receptores, no bojo da construção das práticas culturais, da construção da cidadania. É desse lugar que devemos nos relacionar com eles".

E da inter-relação entre Comunicação e Educação emerge também o diálogo com a esfera do Consumo - fazendo manifestar-se o campo Comunicação/Educação e Consumo, como propõe Baccega ${ }^{10}$ - , prática que repercute a partir da comunicação e que ganha força na cultura contemporânea - que se constrói na disputa entre simbólico e material. Consumo compreendido enquanto prática sociocultural que produz significados, define identidades e confere sentimento de pertencimento a um grupo.

O consumo, portanto - na linha de pensamento de Martín-Barbero ${ }^{11}$, que propõe cinco concepções de consumo apoiando-se nos estudos de Canclini, Castells e Bourdieu —, introduzido em todo um âmbito cultural e simbólico que se acresce ao simplesmente material do senso comum. E sendo o consumo um campo proeminente hoje, Baccega defende que estudar o consumo é concretizar o exercício da cidadania'12: "[...] o conhecimento crítico das práticas de consumo faz parte da formação de sujeitos conscientes, objetivo primeiro do processo educacional"13. Educação enquanto força emancipatória no sentido de que pode formar cidadãos conscientes, críticos, reflexivos e com autonomia de pensamento.

E assim concluímos e evidenciamos nosso sustentáculo teórico que inicia e termina na Educação, passando pelas questões do Consumo e da Cidadania, que são, de fato, os dois conceitos que, trabalhados teoricamente aqui, são analisados empiricamente na sequência, nos nos discursos de jovens receptores das letras do Racionais MC's.
3 COSTA, Maria Eugênia Belczak. Grupo focal. In: DUARTE, Jorge e BARROS, Antônio. Métodos e técnicas de pesquisa em comunicação. 2. ed. São Paulo: Atlas, 2011, p. 181.

4 BRANDÃO, Helena $\mathrm{H}$. N. Introdução à análise do discurso. Campinas: Unicamp, 2004

5 ORLANDI, Eni P. Análise de discurso: princípios e procedimentos. 8. ed. São Paulo: Pontes, 2009.

6 Idem, p. 20.

7 DAGNINO, Evelina. Os movimentos sociais e a emergência de uma nova noção de cidadania. In: DAGNINO, Evelina (org.). Os anos 90: política e sociedade no Brasil. São Paulo: Brasiliense, 1994, pp. 103-115.

8 Idem, p. 109.

9 BACCEGA, Maria Aparecida. Comunicação e consumo: educação e cidadania. In: ROCHA, Rose de Melo e OROFINO, Maria Isabel Rodrigues. Comunicação, consumo e ação reflexiva: caminhos para a educação do futuro. Porto Alegre: Sulina, 2014, p. 194.

10 Idem, p. 202.

11 MARTÍN-BARBERO, Jesús. América Latina e os anos recentes: o estudo da recepção em comunicação social. In: SOUZA, Wilton de (org.). Sujeito, o lado oculto do receptor. São Paulo: Brasiliense, 2002, pp. 61-63.

12 BACCEGA, Maria Aparecida, op. cit., p. 197.

13 Idem, p. 201. 


\section{COMPREENSÃO DO LUGAR DE FALA DO GRUPO RACIONAIS MC'S}

Segundo a Central Única das Favelas (Cufa) $)^{14}$, o rap (abreviatura de rhythm and poetry, que, do inglês, significa ritmo e poesia) chega ao Brasil, mais especificamente à cidade de São Paulo, em 1986, trazendo às periferias batidas rápidas e aceleradas e discursos com mais informação e menos melodia, que denunciam as dificuldades que se descortinam no cotidiano dos moradores de bairros pobres. De acordo com Carmo ${ }^{15}$, a dupla Thaíde e DJ Hum é a pioneira do gênero no país. Na pauta dessa recém-chegada vertente musical, o tom de denúncia impera e incomoda.

No bojo do rap brasileiro, detemo-nos em nosso estudo a um dos grupos pioneiros - o Racionais MC's —, constituído em 1988, no Capão Redondo, bairro localizado na periferia da Zona Sul de São Paulo, considerado um dos mais violentos da cidade ${ }^{16}$. Entre seus integrantes, estão Mano Brown (Pedro Paulo), Ice Blue (Paulo Eduardo Salvador), Edi Rock (Adivaldo Pereira Alves) e KL Jay (Kleber Geraldo Lelis Simões). Desde os seus primeiros trabalhos que compreendem a gravação, em 1988, de faixas nas coletâneas Consciência Black, Pânico na Zona Sul e Tempos Difíceis —, o Racionais MC's passa a narrar a vida sofrida de quem é negro e pobre no Brasil, colocando, em seu discurso, o racismo e o sistema capitalista como opressor e patrocinador da miséria que, por sua vez, reverbera na violência e no crime ${ }^{17}$.

Boa parte da trajetória dos fios constitutivos dessa narrativa pode ser encontrada no site oficial da banda, criado por ocasião da celebração de 25 anos do grupo ${ }^{18}$. O sucesso, como o próprio grupo aponta no site, foi o ter-

14 CUFA. O que é rap? Disponível em: <http:// cufasinop.blogspot.com. br/2009/06/o-que-e-rap. html>. Acesso em: 9 set. 2013.

15 CARMO, Paulo Sérgio do. Culturas da rebeldia: a juventude em questão. São Paulo: Senac, 2001.

16 EXAME. As 10 regiões mais perigosas de São Paulo. Disponível em: <http://exame.abril.com. $\mathrm{br} / \mathrm{brasil} /$ noticias/as-10-regioes-mais-perigosas-de-sao-paulo>. Acesso em: 09 set. 2014.

17 RACIONAIS MC'S 25 ANOS. História. Disponível em: <www. racionais25.com. br/sample-page>. Acesso em: 10 out. 2014.

18 RACIONAIS MC'S 25 ANOS. Home. Disponível em: <www.racionais25. com.br>. Acesso em: 10 out. 2014. ceiro disco - Raio X Brasil —, lançado na quadra da escola de samba Rosas de Ouro. Desde então há o que, para o grupo, constitui-se em hinos nas periferias brasileiras, como as músicas "Fim de semana no parque" e "Homem na estrada".

Já em 1997, com chancela de seu próprio selo (Cosa Nostra), é lançado Sobrevivendo no Inferno e, no ano seguinte, vencem os prêmios Melhor Grupo de Rap e Escolha de Audiência do Video Music Brasil (VMB), premiação realizada pela MTV, emissora dedicada ao público jovem. No ano de 2009, o Racionais MC's recebe da Cufa o prêmio Hutúz, na categoria Melhores Artistas da Década. Em 2012, a trajetória do grupo é brindada com mais um prêmio no VMB pelo videoclipe da música "Mil faces de um homem leal”, que fala de Marighella, militante brasileiro que lutou contra a ditadura no país.

Após uma trajetória recheada de premiações e reconhecimentos, a postura comumente fechada, arisca à mídia, cede, hoje, espaço para um grupo que procura se aproximar mais de seu público, de seus fãs. Isso se ratifica com o lançamento, em 2014, do site oficial, o canal no YouTube (Racionais TV) em 2012 e, no ano de 2013, os perfis no Facebook. 


\section{A RECEPÇÃO DO RAP ENTRE ESTUDANTES PAULISTANOS}

Por meio dos estudos de recepção, buscamos entender como são construídas as interações que ocorrem no bojo da sociedade e como se desenvolve esse processo de negociação de sentidos. Afinal, "não podemos estudar a recepção sem analisar essas dimensões de exclusão que hoje continuam vivas em nossa sociedade, por mais transformações que tenham havido"19.

Assim, neste momento, apresentamos concretamente as análises alcançadas com o estudo de recepção empreendido através de focus group realizado com estudantes de Comunicação, entre 20 e 25 anos, de duas faculdades particulares de São Paulo, de classe média e média alta, com o objetivo de verificarmos quais são as suas percepções frente às músicas do Racionais MC's - selecionamos duas músicas para serem analisadas pelo grupo, "Capítulo 4, versículo 3" e "Vida Loka (parte 2)". Enfim, buscamos compreender as percepções dos estudantes acerca de questões sociais, da periferia e do consumo; e entender como recebem as mensagens das músicas do rap a partir de suas práticas sociais.

Primeiro, sobre o rap, conseguimos discursos representativos como os que seguem. Para um dos entrevistados, a questão da narrativa do rap "é muito forte, talvez é muito mais forte do que em outros gêneros. É um coisa que está relacionada a um realidade sofrida ou por outro lado, talvez, uma questão de fuga... fugir um pouco desse cotidiano". Já para outro entrevistado, o rap é a "salvação para muitas pessoas", "algo que foge completamente de música". Ainda, para mais um integrante do grupo: "O rap é um hino das pessoas que vivem naquelas condições [adversas]. É uma forma de comunicar para as pessoas que estão fora do rap como é a condição de vida fora dele". E, por fim, outro integrante acredita que o rap "fala da realidade, não é uma coisa irreal, está falando de uma coisa que vive realmente. Às vezes pode nem estar vivendo mais, mas da realidade que ele viveu".

Em relação especificamente ao Racionais MC's, cujas letras seriam analisadas posteriormente, os participantes expõem inicialmente, espontaneamente, declarações como as que selecionamos na sequência. O Racionais MC's "contam fábulas da vida real, tratam da realidade", profere um entrevistado. Segundo outro entrevistado, essa realidade é mostrada "com uma lente muito negativa, um lado que não é estereotipado, uma periferia real". "Essa realidade que sangra, o mais obscuro, que não está retratando as pessoas felizes e alegres", completa outro entrevistado.

$\mathrm{Ou}$ seja, para aqueles que nunca tiveram um contato profundo com a periferia, seu retrato talvez seja fornecido pela cultura da mídia, no caso, pelo rap, que desenha para o receptor uma dinâmica social e cultural através de representações. "Numa cultura da imagem dos meios de comunicação de massa, são as representações que ajudam a constituir a visão de mundo do indivíduo" ${ }^{20}$.

No geral, para esse grupo pesquisado, os assuntos abordados pelas músicas do Racionais MC's são criminalidade, preconceito, meios de comunicação, consumo e religião. Num primeiro momento o grupo percebeu duas questões abordadas nas letras do Racionais MC's: (1) o preconceito e (2) como este é

19 MARTÍN-BARBERO, Jesús, op. cit., p. 52. 
inserido dentro da realidade retratada nas letras. O negro sofre o preconceito por parte dos brancos, mas também dentro da periferia, onde suas chances são ainda menores do que a do branco pobre, potencializando sua entrada para o mundo do crime.

Ao levantarmos, de forma estimulada, a questão do consumo abordado nas músicas, o grupo surgiu com a discussão que reproduzimos agora. Segundo o primeiro entrevistado, a música mostra que você pode ter tudo de maneira fácil desde que roube, mas também faz a sugestão de que é melhor "ir pelo lado certo da vida". Para outro dos entrevistados, "o capitalismo exclui eles [os negros da periferia] da sociedade, mas ao mesmo tempo quer atrair eles para o consumo". É levantada ainda por um dos integrantes do grupo a questão do consumo como diferenciação.

O consumo é, portanto, o sistema que classifica bens e identidades, coisas e pessoas, diferenças e semelhanças na vida social contemporânea. [...] Bens de consumo expressam nosso lugar na sociedade, quem é próximo ou distante, expressam nosso interiores e, no mesmo processo, expressam as relações dos próprios bens entre $\mathrm{si}^{21}$.

E, por fim, um dos entrevistados defende que o Racionais MC's faz uma crítica ao consumo como "forma de preencher um vazio". E todos concordaram que o rap, em geral, trabalha o consumo com uma visão crítica.

Ainda assim, de forma geral, o grupo analisou o consumo nas letras do Racionais MC's sob uma perspectiva negativa: observou a questão da ostentação abordada no videoclipe relacionando-a ao tráfico e à criminalidade; além da menção ao consumo como exclusão: as imagem do garoto desejando um tênis de marca e não podendo comprar. Como abordou um dos entrevistados, o consumo os atrai, mas os exclui. Vemos aqui o consumo como forma de distinção ${ }^{22}$.

Para finalizarmos a discussão em torno do consumo, fizemos a seguinte pergunta geral ao grupo: na sua opinião, o que é consumo? O primeiro entrevistado respondeu exatamente: "as coisas que você usufrui no seu dia a dia, no

20 KELLNER, Douglas. A cultura da mídia - estudos culturais: identidade e política entre o moderno e o pós-moderno. Bauru: Edusc, 2001, p. 82

$21 \mathrm{ROCHA}$, Everardo; AUCAR, Bruna. Cultura material e convergência da mídia: um estudo sobre a construção da subjetividade contemporânea. In: ROCHA, Everardo; PEREIRA, Cláudia; BARROS, Carla (orgs.). Cultura e experiência midiática. Rio de Janeiro: Editora PUC-Rio/Mauad, 2014, pp. 106-107. decorrer da sua vida, o que você compra e deixa de comprar, o que você precisa e o que você não precisa, porque às vezes a gente usufrui de coisas porque a gente quer, não porque a gente precisa". Segundo outro integrante do grupo, "depende de como você lida com as coisas que estão a sua disposição. Consome porque tem algo a dizer. Consome por entretenimento". Para outro entrevistado o consumo é tudo que satisfaz as "suas necessidades fisiológicas e os desejos". Enquanto para um último integrante o "consumo é uma forma de se colocar socialmente e de construção de identidades".

Vemos que ao ser abordado de forma mais ampla sobre o consumo o grupo trouxe outras visões sobre o tema, diferentemente da questão do consumo nas letras do Racionais MC's. Aqui os entrevistados conseguem enxergar o consumo como forma de construção de identidades, como forma de expressão e realização de desejos. Talvez por conseguirem visualizar situações em que se identificam, situações do seu cotidiano, da sua vida familiar em que o consumo se insere. 
Para finalizar a sessão, o último tema abordado junto ao grupo foi cidadania, a partir do questionamento sobre seu significado para os presentes.

Para um dos entrevistados, cidadania é "uma visão da forma como você se coloca como cidadão na sociedade, [...] cidadania pode ser votar [...], dentro de um sistema que tem questões de cunho moral, e de valores e ética [...]. Então obviamente estar dentro daquelas leis que estão escritas, mas também de um sistema de valores que muitas vezes não está necessariamente escrito, mas está afirmado socialmente. Mas fazer parte de um sistema social e de uma sociedade".

Segundo mais um integrante, cidadania está ligada à "liberdade, direito à vida e propriedade, só que eu acho que vou um pouco além, cidadania é quando você se posiciona no sentido a garantir que todo mundo tenha isso, quando você se posiciona nesse sentido e faz alguma coisa, seja individualmente ou coletivamente, ou você se agrupa em torno de uma coisa".

E concordando com essa posição, um último entrevistado complementou: "Eu acho que a questão da cidadania é também um ajudar o outro, eu acho que isso influencia no desenvolvimento do pais [...], eu acho que cidadania tem muito a questão de ajudar uns aos outros, não só pelo o que está escrito na lei, pelo o que eu tenho que fazer porque é dever, fazer as coisas como voluntário também”.

Todos os entrevistados veem a questão da cidadania como regras, valores a serem seguidos dentro da sociedade. Com exceção de um entrevistado, todos os os demais concordaram que a cidadania não é um ato individual, mas coletivo, em prol do bem-estar geral da população.

\section{CONSIDERAÇÕES FINAIS}

No discurso dos receptores de classe média e média alta paulistana entrevistados, o sentido de periferia é de um local pobre, afastado simbólica ou fisicamente do centro urbano. Simbolicamente porque pode estar totalmente imerso no centro e mesmo assim continuar segregado. Seria, ainda nas palavras destes, um sinônimo de favela. Um local em que a pessoa está lá "porque só pode estar lá". Um lugar que "não é desejado".

E na esfera da recepção, sintetizando, podemos concluir que o consumo, de forma espontânea ou estimulada, ganha dois sentidos principais. O primeiro sentido relaciona o consumo com os males sofridos pelos sujeitos periféricos que, excluídos, na tentativa de inserirem-se na sociedade do consumo, entram para o mundo do crime e aí perdem-se na vida. Sentido que dialoga com o conceito moralista exposto por Rocha:

É a responsabilização do consumo pelas diversas mazelas da sociedade. A simples observação dos discursos cotidianos nos mostra que é muito comum o consumo ser eleito como responsável por uma infinidade de coisas, geralmente associadas aos assim chamados problemas sociais. O consumo explica mazelas tão díspares quanto violência urbana, ganância desenfreada, individualismo exacerbado, ou toda a sorte de desequilíbrios (mental, familiar e, até mesmo, ecológico) da sociedade contemporânea ${ }^{23}$.
22 BOURDIEU, Pierre. A distinção: crítica social do julgamento. São Paulo: Edusp, 2007.

23 ROCHA, Everardo. Culpa e prazer: imagens do consumo na cultura de massa. Revista Comunicação, mídia e consumo, São Paulo, v. 2, n. 3, pp. 123-138, mar. 2005, p. 128. 
Já o segundo sentido de consumo que apareceu entre os receptores entrevistados é muito mais amplo e arejado. Consumo como algo de nível material e/ou imaterial que nos coloca socialmente, a partir de escolhas que fazemos em termos de necessidades e desejos e que estão relacionadas a gostos aos quais queremos responder e a imagens que desejamos projetar.

No geral, não apenas na voz do Racionais MC's, mas do rap como um todo, o rap figura ele próprio como discurso salvador. Foi salvador para os próprios integrantes do Racionais que conseguiram com o rap sair de sua condição periférica, mas salvador também para os sujeitos periféricos ainda anônimos que encontram conforto no rap. Nas palavras de nossos entrevistados, o rap ganha sentidos de salvação e de denúncia. O rap seria "salvação para muitas pessoas", além de "um hino da juventude sofrida" e "um grito de guerra". Discurso que, portanto, propondo-se a denunciar, aponta certo exercício de cidadania.

Cidadania que, aliás, no âmbito da recepção, é bastante difícil de ser verbalizada. Os entrevistados não situam espontaneamente a cidadania como um tema nas músicas do Racionais MC's, mas, quando estimulados, acreditam que as letras atravessam, sim, as questões de cidadania. Entre nossos entrevistados, vemos uma vertente que associa cidadania a toda uma esfera de direitos reservados aos indivíduos. Direitos que, sendo individuais, devem, ainda assim, obedecer a todo um sistema de valores firmados socialmente para que um sujeito não prejudique o próximo. E aí a segunda vertente de sentidos produzidos em torno de cidadania envolvem a questão do coletivo, de todos trabalharem juntos em prol do avanço e desenvolvimento de um bem-estar social comum.

Os receptores entrevistados indicam uma capacidade de sobrevivência que passa pelo rap - ou que ele mesmo possibilita e é propulsor. E, assim, o consumo e a cidadania aparecem como potencialidades também para esses sujeitos. Afinal, a "cidadania só se configura quando encarnada em um indivíduo, o cidadão [...] é ele que realiza sua existência, enquanto ela lhe confere uma identidade" ${ }^{24}$; identidade conquistada também pela esfera do consumo.

\section{REFERÊNCIAS}

BACCEGA, Maria Aparecida. Comunicação e consumo: educação e cidadania. In: ROCHA, Rose de Melo e OROFINO, Maria Isabel Rodrigues. Comunicação, consumo e ação reflexiva: caminhos para a educação do futuro. Porto Alegre: Sulina, 2014.

BOURDIEU, Pierre. A distinção: crítica social do julgamento. São Paulo: Edusp, 2007.

BRANDÃO, Helena H. N. Introdução à análise do discurso. Campinas: Unicamp, 2004.

CARMO, Paulo Sérgio do. Culturas da rebeldia: a juventude em questão. São Paulo: Senac, 2001. 
COSTA, Maria Eugênia Belczak. Grupo focal. In: DUARTE, Jorge e BARROS, Antônio. Métodos e técnicas de pesquisa em comunicação. 2. ed. São Paulo: Atlas, 2011.

CUFA. O que é rap? Disponível em: <http://cufasinop.blogspot.com. br/2009/06/o-que-e-rap.html>. Acesso em: 9 set. 2013.

DAGNINO, Evelina. Os movimentos sociais e a emergência de uma nova noção de cidadania. In: DAGNINO, Evelina (org.). Os anos 90: política e sociedade no Brasil. São Paulo: Brasiliense, 1994.

EXAME. As 10 regiões mais perigosas de São Paulo. Disponível em: <http:/ / exame.abril.com.br/brasil/noticias/as-10-regioes-mais-perigosas-de-saopaulo>. Acesso em: 9 set. 2014.

FERREIRA, Nilda Teves. Cidadania: uma questão para a educação. Rio de Janeiro: Nova Fronteira, 1993.

KELLNER, Douglas. A cultura da mídia - estudos culturais: identidade e política entre o moderno e o pós-moderno. Bauru: Edusc, 2001.

MARTÍN-BARBERO, Jesús. América Latina e os anos recentes: o estudo da recepção em comunicação social. In: SOUZA, Wilton de (org.). Sujeito, o lado oculto do receptor. São Paulo: Brasiliense, 2002.

ORLANDI, Eni P. Análise de discurso: princípios e procedimentos. 8. ed. São Paulo: Pontes, 2009.

RACIONAIS MC'S 25 ANOS. História. Disponível em: <www.racionais25.com. br/sample-page>. Acesso em: 10 out. 2014.

RACIONAIS MC'S 25 ANOS. Home. Disponível em: <www.racionais25.com. br>. Acesso em: 10 out. 2014.

ROCHA, Everardo. Culpa e prazer: imagens do consumo na cultura de massa.

Revista Comunicação, mídia e consumo, São Paulo, v. 2, n. 3, pp. 123-138, mar. 2005.

; AUCAR, Bruna. Cultura material e convergência da mídia: um estudo sobre a construção da subjetividade contemporânea. In: ROCHA, Everardo; PEREIRA, Cláudia; BARROS, Carla (orgs.). Cultura e experiência midiática. Rio de Janeiro: Editora PUC-Rio/Mauad, 2014.

24 FERREIRA, Nilda Teves. Cidadania: uma questão para a educação. Rio de Janeiro: Nova Fronteira, 1993, pp. 19-20. 